\title{
Gender discrimination in Agricultural land access: Implications for food security in Ondo State, Nigeria
}

\author{
A. G. Adekola ${ }^{1}$, F. O. Adereti ${ }^{2 \star}$, G. F. Koledoye ${ }^{2}$ and P. T. Owombo ${ }^{3}$ \\ ${ }^{1}$ Department of Agricultural Economics and Extension, Igbinedion University, Okada, Edo State, Nigeria. \\ ${ }^{2}$ Department of Agricultural Extension and Rural Development, Obafemi Awolowo University, Ile Ife, Osun State, Nigeria. \\ ${ }^{3}$ Department of Agricultural Economics, Obafemi Awolowo University, Ile Ife, Osun State, Nigeria.
}

Accepted 31 May, 2012

\begin{abstract}
This study assessed gender discrimination in agricultural land access: Implications for food security in Ondo State Nigeria. Specifically, it analysed men and female accessibility to forms of land holding and the factors affecting agricultural land accessibility in the study area. Multistage sampling technique was used in selecting 240 respondents used for this study. Data collected were summarized using descriptive statistics such as frequency counts and percentages and correlation analysis was used to test the hypothesis stated. The results revealed that the mean age of the male respndents was 48.3 while that of female was 43.7 with the standard deviation of 14.9 and 11.3 , respectively. Also, at $p \leq 0.05$, there was significant relationship between accessibility to agricultural land and male and female socio-economic characteristics such as age $(r=0.484)$, marital status $(r=0.568)$, farm size $(r=0.504)$, farming experience $(r=0.479)$, household $(r=-0.668)$, access to credit facility $(r=0.476)$, and membership of social organization $(r=0.593)$. This study therefore concluded that gender differentials, especially with regards to land favour the males. It is therefore recommended that redesigning and redeveloping the structure of land policies to be more gender sensitive and inclusive.
\end{abstract}

Key words: Gender, land acess, food security, correlation, discrimination.

\section{INTRODUCTION}

In a rapidly changing world, food and agricultural land holding systems in developing countries are facing new and increasingly complex challenges (Derman et al., 2007). Fighting poverty, ensuring food and nutrition security while protecting the environment still remains a major challenge facing global development practitioners today. In discussing agriculture, two key factors that cannot be ignored are land and labour. Land ownership, accessibility, and the sustainability of this access are very crucial for any meaningful agricultural development. Either by design or circumstance, women constitute a large proportion of farm labour and agricultural workers. These women usually control very little or no amount of land, which is very important in determining farm productivity

*Corresponding author. E-mail: fadereti@yahoo.com. and labour welfare (Afonja et al., 2002).

Land is the most valuable form of property in agrarian societies because of its economic, political symbolic and ritual importance (Bioye et al., 2006). It is the basis of political power and social status in most societies of the world. It is a productive wealth-creating and life sustaining asset which every human being craves for and provides a sense of identity and rootedness within a community (Argwal, 1994). Land is used for production of biomass, ensuring food, fodder, renewable energy and raw materials for existence of human and animal life. It is a base for settlement and industrial use and a store of our cultural heritage and is actually a source of raw materials like minerals, clay, energy and water (Blum, 1998). Land stands for continuity of ownership since it is a burial ground where all clansmen are buried and consequently a central place for the spirits of their ancestors for example in African countries. 
In most developing countries, land is not only the primary means for generating livelihoods but often the main vehicle for investing, accumulating wealth, and transferring it between generations. Thus, the ways in which access to land is regulated, property rights are defined, and ownership conflicts are resolved has broad implications for food security (Deininger and Binswanger, 1999, FAO, $2006,2008,2009)$. Access to land can be through right of ownership, through informal concessions granted by individuals to kin or friends. Legal ownership is normally accompanied by legal restrictions on disposal, that is, there is no effective control here. In most African societies, women have land use priorities from husbands but have no independent rights which allow them control or produce from the land. The direct advantage of land rights are that a woman can use it to grow food crops, fodder for animals, keeping livestock, practicing sericulture, growing trees and vegetable gardening (Cousins and Claassens, 2006). Land rights facilitate access to credit and strengthen support that the women receive from relatives. Access to land means reliable food supply, better healthcare, better housing and reliable income in most cases.

The percentage of men and women employed in agricultural sector decreased between 1997 and 2008 (due to the increasing industrialization of the considered countries), the percentage of women employed in agriculture is still higher in almost all developing regions as shown in apendix 1 . In the last years, migration of men towards the cities led to a gradual feminization of smallscale agriculture, with an increasing percentage of womenheaded households in rural areas (FAO, 2008). The relevance of women's agricultural labour can be appreciated if we consider that, for instance, the agricultural sector in Sub-Saharan Africa contributes about $30 \%$ of the GNP of the continent, employing from 60 to $90 \%$ of the population and producing from 25 to $90 \%$ of the income deriving from exports (FAO, 2009) and FAO (2002)

Lawanson (2010) opined that Nigeria is a typical patriarchic society where male superiority and dominance originated from historically rooted culture and religion. In Pre-colonial times, females generally were accorded less value and lower social status. Western culture reinforced this anomaly. However, Bruce and Lloyd (1991) stated that the western culture has failed to address gender inequality in access to land, in spite of the role that land plays in the lives of the women who are increasingly being saddled with the responsibility of heading and maintaining households, especially in developing countries.

Women constitute over $50 \%$ of the Nigerian population, make up about $37 \%$ of the formal sector (World Bank, 2001), and dominate the informal economic sector which is principally made up of home-based enterprises (Soetan, 2002); Moreso, Lawanson (2010) stated that their relative powerlessness both economically and politically, are unable to exercise control over resources, particularly land. Some cultures in Nigeria, through marriage and inheritance practices, prohibit women from owning land. However,
Soetan (2002) posited that marital status increases the women ability to own land.

At rural level, women work mainly on their own, linking their activities to the family needs, and just a small percentage of them, everywhere lower than men's receives a wage. In Latin America, for instance, only $2.3 \%$ of women in agriculture get a wage against $20.9 \%$ of men; in Southern Asia salaried rural women are $11.9 \%$, while men are $21.8 \% 7$ (Alice, 2008). With the increasing roles of rural women in agriculture and contributions to food security and the consequence inequality on land access across gender, there is therefore the need to access the gender discrimination in land accessibility and implications to food security in Nigeria

The specific objectives for the study were to:

1. Examine the socio-economic characteristics of the respondents

2. Analyse male and female accessibility to forms of land holdings in the study area

3. Assess the factors affecting male and female accessibility to land.

4. Profile the security of tenue over land across gender.

Hypothesis for this study was stated in the null form as follows: there is no significant relationship between selected socio-economic characteristic of male and female respondents and their accessibility to land in the study area.

\section{The study area}

The study was conducted in Ondo State of Nigeria. The state was carved out of the old Oyo state on the $3^{\text {rd }}$ February, 1976 with the capital in Akure. The state covers an area of approximately $15,500 \mathrm{~km}^{2}$ and it is bounded in the south by the Bight of Benin and Atlantic Ocean; north by Ekiti and Kogi States; east by Edo and Delta States and west by Osun and Ogun states (Figure 1). The state lies between longitude $5^{\circ} 45^{\prime}$ and $7^{\circ} 52^{\prime}$ on the North - South Pole, and longitude $4^{\circ} 20^{\prime}$ and $6^{\circ} 5^{\prime}$ on the East - West Pole. According to analytical report of the National Population Commission (NPC) (2006), Ondo State has $3,441,024$ million people with eighteen (18) Local Government Areas.

The tropical climate of the state is broadly of two seasons: rainy season (April to October) and dry season (November to March). A temperature throughout the year ranges between 21 to $29^{\circ} \mathrm{C}$ and humidity is relatively high. The annual rainfall varies from $2,000 \mathrm{~mm}$ in the southern areas to $1,150 \mathrm{~mm}$ in the northern areas. The soils derived from the basement complex rocks are mostly well drained, with a medium to fine texture. The state enjoys luxuriant vegetation with high forest zone (rain forest) in the south and sub-savannah forest in the northern fringe. The indigenes of the state belong to the Yoruba ethnic group 


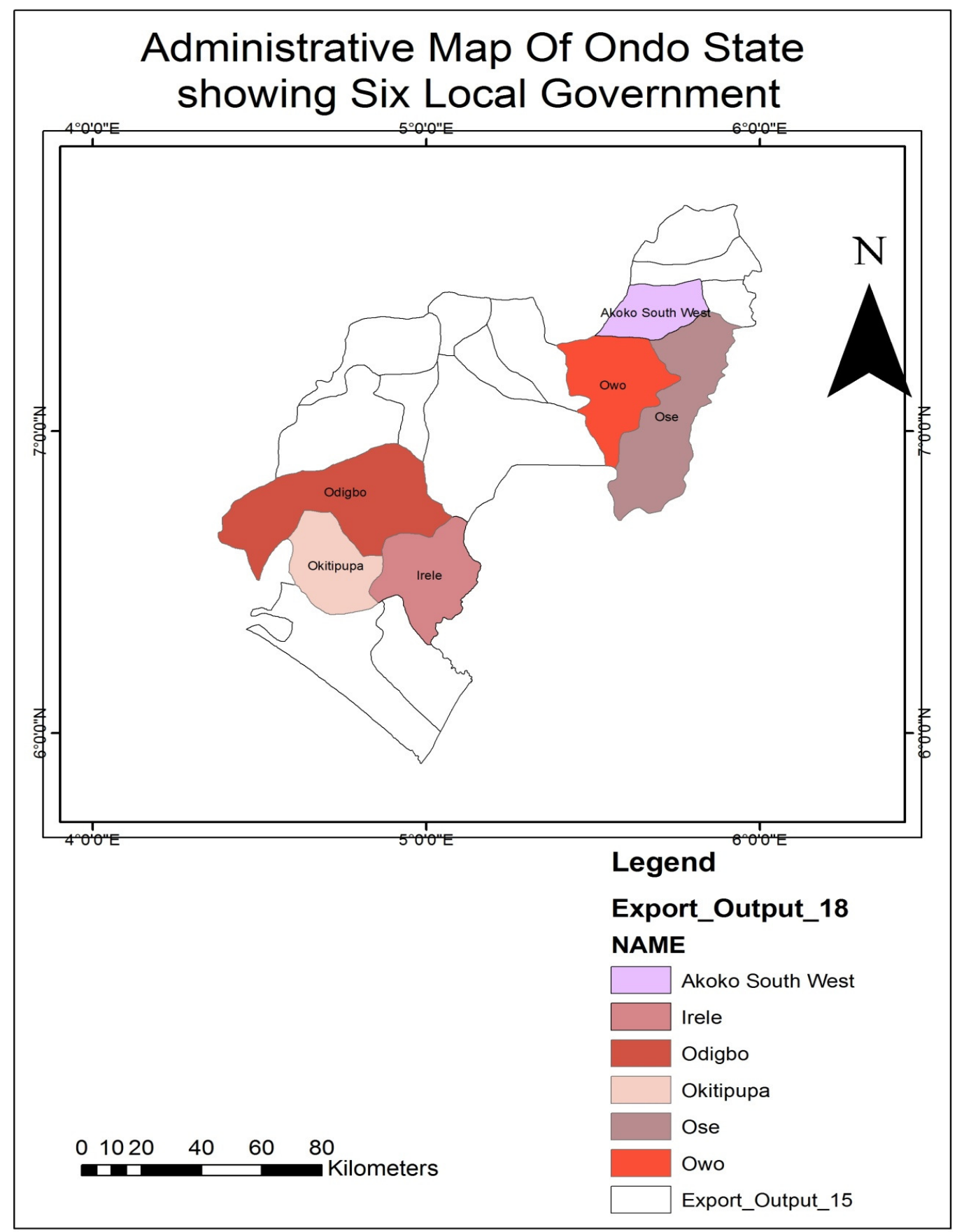

Figure 1. Map of the study area.

and are composed of the Akokos, the Ondos, the Ikales/llajes and the Apoi/ljaw Arogbos. However, non indigenes from every part of the country and outside reside in the state. Yoruba and English are the languages of the people for official and business transactions. The State is basically agrarian with large scale production of cocoa, palm produce and rubber. Other crops like maize, yam and cassava are produced in large quantities. Sixty-five percent of the state labour force is in the agriculture sub-sector
(Coastalnews, 2012). The state is also blessed with very rich forest resources where some of the most exotic timber in Nigeria abounds. Ondo State is equally blessed with extensive deposits of crude oil, bitumen, glass sand, kaolin, granites and limestone. Therefore, the state has great potentials for rapid industrial growth in view of its raw materials base. Reasonable segment of the populace are also traders and artisans. Other occupations of the people include weaving, mat - making, dying, soap making, wood 
Table 1. Distribution of respondent's demographic characteristics.

\begin{tabular}{lcccc}
\hline \multirow{2}{*}{ Variable } & \multicolumn{2}{c}{ Male $(\mathbf{N}=\mathbf{1 6 0})$} & \multicolumn{2}{c}{ Female (N=160) } \\
\cline { 2 - 5 } Age & Frequency & Percentage & Frequency & Percentage \\
$>30$ & 42 & 27.2 & 34 & 21.3 \\
$31-60$ & 90 & 56.3 & 102 & 63.8 \\
60 years and above & 28 & 16.5 & 24 & 14.9 \\
Level of education & & & & \\
No formal education & 19 & 11.9 & 31 & 19.4 \\
Primary school & 56 & 35.0 & 61 & 38.1 \\
Secondary education & 63 & 39.3 & 50 & 31.2 \\
Tertiary education & 22 & 13.8 & 18 & 11.3 \\
Farming experience & & & & \\
$<5$ & 10 & 6.3 & 5 & 3.1 \\
$6-10$ & 32 & 20.0 & 40 & 25.0 \\
$11-20$ & 68 & 42.5 & 79 & 49.4 \\
$>20$ & 50 & 31.2 & 36 & 22.5 \\
Household size & & & & \\
$>2$ & & & & \\
$2-5$ & 15 & 9.4 & 12 & 7.5 \\
$6-9$ & 35 & 21.9 & 89 & 55.6 \\
$>10$ & 84 & 52.5 & 40 & 25.0 \\
Farm size & 26 & 16.2 & 19 & 11.9 \\
$<1$ & & & & \\
$1-3$ & 12 & 7.5 & 62 & 38.8 \\
$>3$ & 91 & 56.8 & 15 & 51.9 \\
\hline
\end{tabular}

Source: Field survey, 2010.

carving, among many others. The state lies entirely within the tropics of $162 \mathrm{~mm}$ per annum.

\section{SAMPLING PROCEDURE}

A multi-stage sampling technique was adopted to select respondents for this study. The first stage involved purposive sampling of six local government areas based on their degree of involvement in farming. The local government areas were Irele, Okitipupa, Odigbo, Owo and Akoko, Ose and Akoko South-West. In the second stage, the local government areas were grouped into communities. In the third stage, two communities were randomly selected from each of the local government areas. In the final stage, twenty respondents with equal number of male and female were sampled from each of the communities

Primary data were used for this study. Data were collected using structured questionnaire and interview schedule for both the literates and illiterates respondents respectively. A total of 240 respondents were used for this study.

\section{Analytical technique}

Data were analyzed using descriptive statistics and inferential statistics. The descriptive statistics employed were frequency counts and percentage while the inferential statistics were correlation analysis and Chi-Square. Data were analysed with the aid of Statistical Package for Social Sciences (SPSS) version 14.0 and CoStat analytical software.

\section{RESULTS AND DISCUSSION}

The result of the socio-economic characteristics as shown in Table 1 revealed that $27.2 \%$ of male respondents were less than 30 years, $56.3 \%$ were found within the age bracket of 31 to 60 years while only $16.5 \%$ were 61 year sand above. In the female category, $21.3 \%$ of the respondents were less than 30 years, $63.8 \%$ were within the age group of 31 to 60 years while just $14.9 \%$ of the respondents were 60 years and above. The mean ages of male and female respondents were 48.3 and 43.7 years respectively. The findings revealed that majority (56.3 and $63.8 \%$ ) of respondents were in their middle active ages, an indication that they will still be active to access land. Furthermore, $35.0 \%$ of male respondents had primary education, $39.3 \%$ had secondary education and only $13.8 \%$ had tertiary education while $11.9 \%$ did not have 
Table 2. Distribution of respondents' accessibility to forms of land holdings.

\begin{tabular}{lcccc}
\hline Gender & \multicolumn{2}{c}{ Male (N=160) } & \multicolumn{2}{c}{ Female (N=160) } \\
\hline Variable & Frequency & Percentage & Frequency & Percentage \\
\hline Access to community land & 152 & 95.0 & 38 & 23.8 \\
Access to inherited land & 138 & 86.3 & 52 & 32.5 \\
Access to land by purchase & 160 & 100.0 & 72 & 45.0 \\
Access to land by lease & 160 & 100.0 & 61 & 38.1 \\
Access to land by gift & 115 & 71.9 & 29 & 18.1 \\
\hline
\end{tabular}

Source: Field survey, 2010. Multiple responses were given.

Table 3. Chi-Square analysis showing the difference between gender and land accessibility.

\begin{tabular}{lcccc}
\hline Variable & $\mathbf{X}^{2}{ }_{\mathbf{c}}$ & $\mathbf{X}^{2}{ }_{\mathbf{t}}$ & $\mathbf{D f}$ & $\mathbf{C}$ \\
\hline Gender & $5.83^{*}$ & 3.84 & 1 & 0.57 \\
\hline
\end{tabular}

P-Values at 0.05 level of significance; $\mathrm{C}=$ Contingency coefficient; $\mathrm{X} 2 \mathrm{c}=$ Chi- square calculated; $\mathrm{X} 2 \mathrm{t}=$ Chi-square

formal education. In the female group, $38.1 \%$ had primary education and only few (11.3\%) had tertiary education. This implied that male respondents were more educated than their female counterparts in the study area. For farming experiences in years, majority $(42.5 \%)$ of male respondents had between 11 to 20 years and $31.2 \%$ had greater than 20 years. More so, $49.4 \%$ of female respondents had 11 to 20 years of farming experience while only $22.5 \%$ were found to have more than 20 years of farming experience as shown in Table 1.

In addition, majority (52.5\%) of male respondents had between 6 to 9 household sizes while majority (55.6\%) of female respondents had between 2 to 5 household sizes. This implied that male respondents had higher household sizes than the female. This could be as a result of male having more than one wives. Also, $56.8 \%$ of male respondents had between 1 to 3 hectares farm size, 35.7\% had more than 3 hectares farm size while $51.9 \%$ of female respondents had between 1 to 3 hectares and a few (9.3\%) cultivated more than 3 hectares of land in the study area. This analysis shows that male respondents had higher farm size than their female counterparts in the study area.

Results in Table 2 revealed that majority (95.0\%) of male respondents had access to communal land while few $(23.8 \%)$ of female respondents had access to community land. Also, $86.3 \%$ of male had access to inherited land while only $32.5 \%$ of female respondents had access to inherited land. More so, $100.0 \%$ of male respondents were found to have access to land by purchase while only $45.0 \%$ of female could access land by purchase. In addition, majority $(71.9 \%)$ of male could access land through gift. The above analyses indicated that male had more access to any form of land than their female counterparts. Also, the result of Chi-Square analysis revealed that there was a significant difference between gender and accessibility to land at 0.05 level of significance as shown in Table 3 .
Gender was found to exert a little above avarage (57\%) strenght of association on land accessibilty. This significant difference further revealed that male have more access to tabulated; Df = degree of freedom; Source: Field survey, 2010. land than female in the study area. This finding was in conformity with Lawanson (2010), Bruce and Lloyd (1991) and Afonja et al. (2002). The low accessibility of female to agricultural land could be as result of sociocultural factors that could hinder female from owning land (Lawanson, 2010).

Results in Table 4 revealed that $70.0 \%$ of male respondent indicated that income level affects land holding, while majority $(100.0 \%)$ of female indicated that marital status is the major determinant to hold land in the study area. More so, about 84.5 percent of the female respondents viewed cultural belief as a factor that affects land holding while a few (38.8\%) of the male respondents indicated that cultural belief is a factor that affects land holding among men in the study area. This finding revealed that men were less affected by the various factors indicated, an indication that female were not having equal access to agricultural land despite their contributions to the food production in Sub-Saharan Africa. This affirms the position of Alice (2008) in the study "effect of land tenure system on women's knowledge-base and resource management in Manjiya County, Uganda". The study indicated that a very low percent of women in agriculture gets a wage as aginst the percentage of men. The Pearson correlation analysis revealed that marital status was positively correlated with land accessibility. This conforms with Soetan (2002).

\section{Multiple responses were given}

On the security of tenure over land, results in Table 5 indicated that about 83.1 percent of male owned land while only few $(17.5 \%)$ of women owned land in the study area. More so, about 74.4 percent of male had been in possession of their land for more than 5 years while about $1.3 \%$ of women had held land for the same duration with men. In addition, about $88.1 \%$ of male had the rights to transfer land while none of the female respondents had the same priviledge of transferring land like their male counterparts. This analysis reveals that gender differential 
Table 4. Factors affecting land ownership.

\begin{tabular}{lcccc}
\hline \multirow{2}{*}{ Variable } & \multicolumn{2}{c}{ Male $\mathbf{( N = 1 6 0 )}$} & \multicolumn{2}{c}{ Female $(\mathbf{N}=\mathbf{1 6 0})$} \\
\cline { 2 - 5 } & Frequency & Percentage & Frequency & Percentage \\
\hline Income & 112 & 70.0 & 129 & 80.6 \\
Marital status & 70 & 43.8 & 160 & 100.0 \\
Access to credit facility & 132 & 82.5 & 108 & 67.5 \\
Age & 125 & 78.1 & 115 & 71.9 \\
Cultural belief & 62 & 38.8 & 135 & 84.5 \\
\hline
\end{tabular}

Source: Field survey, 2010.

Table 5. Security of tenure over land.

\begin{tabular}{lcccc}
\hline \multirow{2}{*}{ Variable } & \multicolumn{2}{c}{ Male } & \multicolumn{2}{c}{ Female } \\
\cline { 2 - 5 } & Frequency & Percentage & Frequency & Percentage \\
\hline Land ownership & & & & \\
Owned & 133 & 83.1 & 28 & 17.5 \\
Otherwise & 27 & 16.9 & 132 & 82.5 \\
& & & & \\
Duration of land use & - & - & 39 & 24.3 \\
$<2$ years & 41 & 25.6 & 118 & 73.8 \\
3-5 years & 119 & 74.4 & 3 & 1.9 \\
$>5$ years & & & & \\
& 19 & 11.9 & 160 & 100 \\
Rights to land & 141 & 88.1 & - & - \\
Use only & & & & \\
Transfer & & & & \\
\hline
\end{tabular}

Source: Field survey, 2010.

Table 6. Results of correlation analysis showing the relationship between male and female socio-economic characteristics and accessibility to agricultural land.

\begin{tabular}{lcc}
\hline Variable & Correlation coefficient $(\mathbf{r})$ & Coefficient of determination $\left(\mathbf{r}^{2}\right)$ \\
\hline Age & $0.484^{*}$ & 0.064 \\
Marital status & $0.568^{*}$ & 0.059 \\
Level of education & 0.115 & 0.013 \\
Farm size & $0.504^{*}$ & 0.039 \\
Farming experience & $0.479^{*}$ & 0.121 \\
Household size & $-0.668^{*}$ & 0.072 \\
Access to credit facility & $0.476^{*}$ & 0.141 \\
Membership of social organization & $0.593^{*}$ & 0.154 \\
\hline
\end{tabular}

Source: Field survey, 2010. Critical value of $r=0.427$, Level of significance $=0.05$.

exists in security of tenure over land in the study area. This findins conform with Lawanson (2010), who stated that women relative powerlessness both economically and politically in a typical African setting limits their control over resources, particularly land and also that male superiority and dominance over resources in Nigeria originated from historically rooted culture and religion.

The results of the hypothesis stated and tested on Table
6 revealed that there were positive and significant correlation between accessibility to agricultural land and age $(r=0.484)$; marital status $(r=0.568)$; farm size $(r=$ $0.504)$; farming experience $(r=0.479)$; access to credit $(r=$ $0.476)$ and membership of social organization $(r=0.593)$. The $r$ values were compared with the critical value of $r=$ 0.427 . Household size had negative but significant relationship with respondents' socio-economic characteris- 
tics and accessibility to agricultural land. Only level of education was found to have non significant relationship. The above information established that an increase in the value of the independent variables would result in corresponding relationship between respondents' socioeconomic characteristics and accessibility to agricultural land. The values of coefficient of determination $\left(r^{2}\right)$ further revealed the percentage contribution of the independent variables to agricultural land accessibility. The higher the values of $r^{2}$, the stronger the influence as reflected in the percentage contribution of the significant variables. This information therefore justified these variables as highly significant between respondents' socio-economic characteristics and accessibility to agricultural land.

\section{CONCLUSION AND RECOMMENDATIONS}

Based on the findings of this study, most of the respondents were within their productive age of 31 to 60 years. There was gender differences in land accessibility in the study area as male were found to have more access to agricultural land than their female counterparts. Female were more affected by the factors affecting land holding in Ondo State. Age, marital status, farm size, farming experience; access to credit facility and cultural beliefs were found to determine accessibility to agricultural land in the study area. There is therefore the need for an intensive effort and emphasis on mainstreaming gender in agricultural programmes. This will facilitate the entry of women as active decision makers on issues that relate to food security and income generation. Women are important links to development: they maintain food security and the general well-being of their families/households. Therefore, improving women's status and control over land should be considered as strategically important efforts at all levels in combating the state of food security in the country.

It is therefore recommended that society and government should consider gender in agriculture by restructuring the system of land holding in order to include the vulnerable group as this will have a significant effect on food production in Ondo State and in Nigeria at large. Also, land tenure policies should be restructured to ensure that farmers (male and female) have equal access to agricultural land especially for perennial crops and are able to obtain land on a more permanent basis would be helpful in combating the state of food insecurity in the country.

\section{REFERENCES}

Afonja S, Mills-Tettey R, Amole D (2002). Gender differentials in access to land and housing in a Nigerian city, being monograph of the Center for Girder and Social Policy Studies, Obafemi Awolowo University, IleIfe.

Alice MK (2008). The effect of land tenure system on women's knowledge-base and resource management in Manjiya County, Uganda.

Argwal B (1994). A field of one's own: Cambridge University Press. FAO corporate document repository: current and emerging issues for economic analysis and research, 2010

Blum CL (1998). Land Tenure and Administration in Africa: Land Tenure and resource Access in Africa, IIED/FAO, London.

Bioye TA, Abdul RA, Joseph BO (2006). Women and Land Rights Reforms in Nigeria: Promoting Land Administration and Good Governance 5th FIG Regional Conference.

Bruce J, Lloyd C (1991). Family Research and Policy Issues for the 1990's', in Understanding how resources are allocated within Households.

Cousins B, Claassens A (2006). 'More than simply 'socially embedded': recognizing the distinctiveness of African land rights'. Keynote address at the international symposium on the frontier of land issues: social embeddedness of rights and public policy' Montpellier, May 17-19.

Coastalnews (2012). Profile of Ondo state, Nigeria.

Deininger K, Binswanger H (1999). The Evolution of the World Bank's Land Policy: principles, experience and future challenges', The World Bank Research Observer 14:247-276.

Derman BR Odgaard O, Sjaastad E (2007). Conflicts over Land and Water in Africa. Oxford: James Currey. The World Bank Research Observer 14:247-270.

Food and Agricultural Organization (2002). Assessment of the World Food Security and Nutrition Situation. Background document for the 38th Session of the FAO, Rome, pp. 34-39.

Food and Agricultural Organization, (2006). The State of Food Insecurity in the World Rome.

Food and Agricultural Organization (2008). Gender, Property Rights and Livelihoods in the Era of AIDS.

Food and Agricultural Organization (2009). Gender Equity in Agriculture and Rural Development. A quick guide to gender mainstreaming in FAO's new Strategic Framework.

Lawanson TO (2010). Gender differentials in Nigeria: Implications for sustainable development. J. Extension. Syst. 21(1):46-57.

Soetan R (2002). 'Women, Small Scale Enterprises and Social Change: Implications for Changes in Industrialization Strategy", in Afonja.S and Aina $O$ (eds) Gender and Social Policy Studies. Obafemi Awolowo University, lle lfe

The World Bank (2001). Integrating Gender into the World Bank's Work: A Strategy for Action. www.worldbank.org 


\section{APPENDIX}

Appendix 1. Percentage of women and men employed in the primary sector.

\begin{tabular}{lcccc}
\hline \multirow{2}{*}{ Region } & \multicolumn{2}{c}{$\mathbf{1 9 9 8}$} & \multicolumn{2}{c}{$\mathbf{2 0 0 7}$} \\
\cline { 2 - 5 } & Male & Women & Male & Women \\
\hline World & 39.4 & 42.9 & 33.1 & 36.4 \\
Eastern Asia, South-Eastern Asia and Pacific & 44.3 & 51.6 & 36.4 & 41.2 \\
Latin America and Caribbean & 26.4 & 12.6 & 22.1 & 9.7 \\
Southern Asia & 53.7 & 74.4 & 41.5 & 65.1 \\
Sub-Saharan Africa & 65.1 & 71 & 60.3 & 65.1 \\
\hline
\end{tabular}

Source: Global Employment Trends for Women, ILO, 2009-data for 1998 and 2007 